\title{
An evaluation of phytochemical and biopesticidal composition of scent leaf
}

\author{
II Ujah ${ }^{1, *}$, JI Ugochukwu ${ }^{2}$ and UB Alozieuwa ${ }^{3}$ \\ ${ }^{1}$ Department of Applied Biochemistry, Faculty of Applied Natural Sciences, Enugu State University of Science and \\ Technology, Enugu State Nigeria. \\ 2 Department of Pharmaceutical Microbiology and Biotechnology, Faculty of Pharmaceutical Sciences, Enugu State \\ University of Science and Technology, Enugu State Nigeria. \\ ${ }^{3}$ Department of Biochemistry, Faculty of Natural \& Applied Sciences, Veritas University Abuja, Nigeria.
}

GSC Biological and Pharmaceutical Sciences, 2021, 17(01), 117-123

Publication history: Received on 25 August 2021; revised on 06 October 2021; accepted on 08 October 2021

Article DOI: https://doi.org/10.30574/gscbps.2021.17.1.0281

\begin{abstract}
Phytochemicals are therapeutic while biopesticides are naturally occurring forms pesticides which are eco-friendly. The phytochemicals as well biopesticidal contents of scent leaf were investigated. The result indicated that glycosides and alkaloids not detectable, phenols and terpenoids least present, flavonoids and saponins moderately present while steroids and tannins were high in abundance.The result as investigated showed that scent leaf extract contains various secondary metabolites in the following concentrations, saponins $(0.130 \pm 0.361 \mathrm{mg} / \mathrm{g})$, tannins $(0.133 \pm 0.365 \mathrm{mg} / \mathrm{g})$, flavonoid $(0.033 \pm 182 \mathrm{mg} / \mathrm{g})$ steroid $(0.005 \pm 0.071 \mathrm{mg} / \mathrm{g})$, terpenoid $(0.071 \pm 0.266 \mathrm{mg} / \mathrm{g})$ as well as oxalic acid which is the biopesticidal content. Owing to the phytochemicals and biopesticide in this leaf, scent leaf could be used both therapeutically and as a biopesticide.
\end{abstract}

Keywords: Phytochemicals; Biopesticidal; Glycosides; Alkaloids; Phenols; Terpenoids; Steroids; Tannins; Oxalic acid

\section{Introduction}

Biopesticides have immensely proven both economically and otherwise a great benefit to plants and animals as it can be applied both for curative (in animals) and treatment (in plants) measures. Biopesticides are certain types of pesticides derived natural materials such as animals, plants, and bacteria [1]. In recent years, some environmental problems have aroused the concern of the public on the use of pesticides. There have been studies on the subject of pesticide and human health, but there still remains deep controversy surrounding it [2]. Farmers were in dilemma to either sacrifice a significant of their crops to pest or use highly toxic pesticide that can harm human health and environment [3].

Biopesticides are key elements of Incorporated Insect Management (IIM) programs and are receiving much practical attention as a means to reduce the rate of artificial chemicals of pest control which are being used. Heavy use of synthetic chemicals of pest control started from 1940s and before then, farmers were using natural insecticides such as rotenone, essential oil, pyrethroids, and neem oil from roots of demis plants and pyrethrum from flower heads of a species of chrysanthemum [4].

Over the years, it was found that the level of synthetic pesticides were building and were not biodegradable and their harmful effect started coming out which led to a need to create biopesticides which are more effective, eco-friendly and do not leave any harmful effect on the environment [5]. Biopesticides are inherently less toxic than conventional

${ }^{*}$ Corresponding author: II Ujah

Department of Applied Biochemistry, Faculty of Applied Natural Sciences, Enugu State University of Science and Technology, Enugu State Nigeria.

Copyright (C) 2021 Author(s) retain the copyright of this article. This article is published under the terms of the Creative Commons Attribution Liscense 4.0. 
pesticides, it generally affect only the target pest and closely related organism, in contrast to broad spectrum, conventional pesticides that effect organisms different from insects and pest [6]Har. They often are effective in every small quantity and often decompose quickly, thereby resulting in lower exposures and largely avoiding the pollution problems caused by conventional pesticides [7]. When used as a component of Integrated Pest Management (IPM) programs, biopesticides can greatly decrease the use of conventional pesticides, while crop yields remain high. To use biopesticides effectively, however, users need to know a great deal about management pest [6].

Scent leaf is a well know medicinal plant and has been used as a traditional agent for numerous human diseases since ages in many part of the world [8]. In rural areas of the developing countries, they are the primary source of medicine [9]. Scent leaf has been used as spice in food and medicinal purposes shown to have antibiotic, antiviral and antifungal qualities. Scent leaf exhibits a broad antibiotic spectrum against Gram positive and Gram negative bacteria. Other therapeutic effects of scent leaf include lowering of cholesterol levels, blood pressures, immune system boosting and treatment of infections such as athlete's foot, convulsion, antioxidant effects as well as anti-asthmatic effect [8].

Scent leaf aids digestion. It improves immunity and contributes to the general sense of wellbeing. It is also an important substance regarding the production of biopesticides which helps in controlling of pests such as mosquitoes. Scent leaf has a warming antiseptic qualities and ability to normalize cholesterol, blood pressure and help also to reduce the effects of cold, flu, cough and other bacterial infections [10]. The research aimed at assessing the phytochemical and biopesticide content of scent leaf.

\section{Methods}

\subsection{Sample collection}

The sample used Ocimum gatissium (Scent leaf) were obtained from Ogbete main market, Enugu State, Nigeria.

\subsection{Sample preparation}

The sample scent leaf was separated from the stem by hand picking and were air-dried at room temperature before grinding to form a powder using an electric grinder. The grinding was repeated severally to obtain the finest surface area and the ground leaf kept in an air-tight container.

\section{Qualitative analysis}

\subsection{Tannins}

A quantity, $0.1 \mathrm{~g}$ of extract was stirred with $10 \mathrm{ml}$ of distilled water and filtered; few drops of $1 \%$ ferric chloride solution were added to $2 \mathrm{ml}$ of each filtrate. The presence of a blue-black indicated the presence of tannins [11].

\subsection{Alkaloids}

A quantity, $0.1 \mathrm{~g}$ of the extract was dissolved individually in dilute hydrochloric acid and filtered. Filtrates were treated with Dragendroff's reagent, formation of red precipitate indicated the presence of alkaloids [11].

\subsection{Saponins}

A quantity, $0.1 \mathrm{~g}$ of the extract was boiled with $5 \mathrm{ml}$ of distilled water and filtered. To each filtrate, about $3 \mathrm{ml}$ of distilled water was further added and shaken vigorously for about 5 mins. Frothing which persisted on warming was taken as an evidence for the presence of saponins [12].

\subsection{Glycosides}

A quantity, $0.1 \mathrm{~g}$ of the extract was mixed with $30 \mathrm{ml}$ of distilled water and heated on a water bath for $5 \mathrm{mins}$. To $5 \mathrm{ml}$ of each of the filtrates, $0.2 \mathrm{ml}$ of Fehling's solution A and B were added until it turned alkaline. The solutions were heated on a water bath for 7 mins. A brick -red precipitate indicated the presence of glycoside [12].

\subsection{Terpenoids}

A quantity of the extract, $0.1 \mathrm{~g}$ was dissolved in ethanol. Acetic anhydride $1 \mathrm{ml}$ was added, followed by the addition of concentrated $\mathrm{H}_{2} \mathrm{SO}_{4}$. A change in colour from pink to violet showed the presence of terpenoids [12]. 


\subsection{Flavonoids}

A quantity of the extract, $0.1 \mathrm{~g}$ was dissolved in water and filtered. To $5 \mathrm{ml}$ of each of the filtrates, $3 \mathrm{ml}$ of lead ethanoate solution was added. Appearance of a buff-colour (pale yellow - brown) precipitate indicated the presence of flavonoids [11].

\subsection{Steroids}

To $0.1 \mathrm{~g}$ of extract, $2 \mathrm{ml}$ of acetic acid was added. The solution was cooled well in ice followed by the addition of conc. tetraoxosulphate (vi) $\left(\mathrm{H}_{2} \mathrm{SO}_{4}\right)$ carefully. Colour development from violet to blue or bluish green indicated the presence of a steroidal ring [12].

\subsection{Phenols}

A quantity of $0.1 \mathrm{~g}$ extract was boiled with distilled water and then filtered. To the filtrate, few drops of $10 \%$ ferric chloride solution were then added. A green-blue or violet colouration indicated the presence of phenolic hydroxyl group [11].

\section{Quantitative analysis}

\subsection{Saponins}

Scent leaf powder was weighed (1.0 g) using an electric weighing balance into $250 \mathrm{ml}$ conical flask and soaked with 100 $\mathrm{ml}$ of $20 \%$ ethanol for three (3) minutes and heated for three (3) hours at $55{ }^{\circ} \mathrm{C}$ for proper extraction and then filtered. The residue was re-extracted with another $100 \mathrm{ml}$ of $20 \%$ ethanol. The two extracts were combined and heated to 40 $\mathrm{ml}$ at $90{ }^{\circ} \mathrm{C}$ on a water bath. The concentrate was transferred into a $500 \mathrm{ml}$ separating funnel and 20 ml of diethylether was added and shaken vigorously, the upper layer was discarded.The purification process was repeated and $60 \mathrm{ml}$ of $\mathrm{n}-$ batanol was added, the lower layer was discarded while the upper layer was collected. The combined n-butanol extract was washed with $10 \mathrm{ml}$ of $5 \%$ aqueous $\mathrm{NaCl}$ and the lower layer was discarded while the upper layer was collected in a weighed beaker and heated to dryness. The beaker is allowed to cool in a desiccator and re-weighed. The saponin content was determined using the following formula.

Concentration of saponin $=\quad \frac{W_{2}-W_{1}}{W_{3}}$.

Where

$\mathrm{W}_{1}=$ weight of empty beaker

$\mathrm{W}_{2}=$ weight of beaker + sample heating

$\mathrm{W}_{3}=$ weight of sample used

\subsection{Tannins}

Scent leaf powder was weighed $(1.0 \mathrm{~g})$ into a plastic bottle and $50 \mathrm{ml}$ of distilled water was added and shaken for 3 hours in a vibrator. The sample was filtered into a $50 \mathrm{ml}$ volumetric flask and made up to mark. A volume, $5 \mathrm{ml}$ of the filtrate was dispensed into a test tube and mixed with $2 \mathrm{ml}$ of $0.1 \mathrm{M} \mathrm{FeCI}_{2}$ in $0.1 \mathrm{~N} \mathrm{HCI}$ and $0.008 \mathrm{M}$ potassium ferrocyamide, the absorbance was measured at $720 \mathrm{~nm}$ for 10 mins. The tanning concentration was determined using the following relation.

Concentration of tannin $=\frac{A b s \times D . F}{1000 \times \text { weight of sample used }}$

Where

Abs $=$ value of absorbance read

D.F = dilution factor 


\subsection{Flavonoids}

Scent leaf powder $(1.0 \mathrm{~g}$ ) was repeatedly extracted with $100 \mathrm{ml}$ of $80 \%$ aqueous methanol at room temperature, the solution was shaken for 30 mins and filtrate was transferred into a weighed beaker and evaporated to dryness over a water bath and weighed again. The time for the first extraction was 1 hour, 45 mins for the second extraction and 30 mins for the third extraction. Flavonoid was determined using the following formula.

Concentration of flavonoid $=\frac{W_{2}-W_{1}}{W_{3}}$

Where

$\mathrm{W}_{1}=$ weight of empty beaker

$\mathrm{W}_{2}=$ weight of beaker + sample after drying

$\mathrm{W}_{3}=$ weight of sample used

\subsection{Steroids}

Scent leaf powder (1.0 g) was dispersed in $100 \mathrm{ml}$ of distilled water into a conical flask; the mixture was shaken for 3 hours and allowed to stand overnight. Then it was filtered, the filtrate was eluted with $10 \mathrm{ml}$ normal ammonium hydroxide solution, $2 \mathrm{ml}$ of the elute was put into a test tube and mixed with $2 \mathrm{ml}$ of chloroform and also $3 \mathrm{ml}$ of acetic hydride was added to the mixture, followed by $2 \mathrm{ml}$ of concentrated $\mathrm{H}_{2} \mathrm{SO}_{4}$ drop wisely. The absorbance was measured in a spectrophotometer at $420 \mathrm{~nm}$.

The steroid concentration was determined using the following relationship.

Concentration of steroids $=\frac{\text { Abs } \times \text { Path length }}{100 \times \text { weigh of sample used }}$

\subsection{Terpenoid content}

A quantity $(0.1 \mathrm{~g})$ of the extract was weighed out separately, macerated with $20 \mathrm{ml}$ of ethanol and filtered through Whatman No.1 filter paper. The filtrates $(1 \mathrm{ml})$ were pipetted out and $1 \mathrm{ml}$ of $5 \%$ phosphomolybdic acid solution was added and shaken. Gradually $1 \mathrm{ml}$ of concentrated $\mathrm{H}_{2} \mathrm{SO}_{4}$ was added to each. The mixtures were left to stand for 30 minutes. Ethanol ( $2 \mathrm{ml}$ ) was added and absorbance was measured at $700 \mathrm{~nm}$.

Concentration of terpenoid $=\quad \frac{\text { Abs } \times \text { Path length }}{100 \times \text { weigh of sample used }}$

\section{Assay of the biopesticidal content of scent leaf}

\subsection{Determination of oxalic acids in scent leaf}

A standard solution of oxalic acid was prepared by dissolving $100 \mathrm{mg}$ of oxalic acid $\left(\mathrm{C}_{2} \mathrm{H}_{2} \mathrm{O}_{4} 2 \mathrm{H}_{2} \mathrm{O}\right.$ mol) in distilled water and diluted to $100 \mathrm{ml}$ with distilled water. A quantity of the powered sample $0.5 \mathrm{~g}$ was transferred to $50 \mathrm{ml}-$ capacity volumetric flask, to which, $30 \mathrm{ml}, 0.25 \mathrm{~N} \mathrm{HCl}$ was added and kept in boiling water bath for about 15 min, cooled to room temperature and volume was made upwith $0.25 \mathrm{~N}$ HCL. This solution was used as extract for determination of oxalic acid.

Assay mixture contained $2 \mathrm{ml}$ standard oxalic acid solution at various concentrations, ranging from 0.100 to $1.00 \mathrm{mg}$ per ml, prepared in $1 \mathrm{~N} \mathrm{H}_{2} \mathrm{SO}_{4}$. Blank was prepared with $2 \mathrm{ml}$ in sulfuric acid instead of oxalic acid solution. Then $2 \mathrm{ml}$ of indole reagent was added in each test tube including blank, allowing the reagent to run down the side of the tube to minimize heat development. All test tubes were placed in water bath at 80 to $90{ }^{\circ} \mathrm{C}$ for 45 minutes, cooled to room temperature and absorbance was measured at $525 \mathrm{~nm}$. 


\section{Results}

\subsection{Phytochemical in scent leaf}

Table 1 shows the pytochemicals in scent leaf. The result indicates high abundance of steroids and tannins, moderate presence of flavonoids and saponins, slight presence of terpenoids while alkaloids and glycosides were not detectable.

Table 1 Phytochemicals in scent leaf

\begin{tabular}{|l|c|}
\hline Parameters & Abundance \\
\hline Alkaloids & ND \\
\hline Glycosides & ND \\
\hline Flavonoids & ++ \\
\hline Steroids & +++ \\
\hline Tannins & +++ \\
\hline Phenols & + \\
\hline Saponins & ++ \\
\hline Terpenoids & + \\
\hline
\end{tabular}

Key $=$ Interpretation; $+++=$ Highly present $;++=$ Moderately present; $+=$ Slightly present; ND= Not detected

\subsection{Quantitative constituents of scent leaf}

Table 2 shows the chemical constituents of scent leaf. The result indicated that terpenoids, tannins and saponinswas the highest chemical constituents in scent leaf, flavoids and steroids contained slightly chemical constituents while phenols, alkaloids and glycosides were not detectable.

Table 2 Chemical constituents of scent leaf

\begin{tabular}{|l|c|}
\hline Parameters & Abundance \\
\hline Saponins & $0.130 \pm 0.361$ \\
\hline Tannins & $0.133 \pm 0.365$ \\
\hline Flavonoids & $0.033 \pm 0.182$ \\
\hline Steroids & $0.005 \pm 0.071$ \\
\hline Terpenoids & $0.071 \pm 0.266$ \\
\hline Phenols & ND \\
\hline Alkaloids & ND \\
\hline Glycosides & ND \\
\hline \multicolumn{2}{|c|}{ KEY WORDS; ND - Not detectable }
\end{tabular}

\subsection{Determination of oxalic acid in scent leaf}

Table 3 shows the determination of oxalic acid in scent leaf. The results indicated that oxalic acid was detectable in scent leaf.

Table 3 Determination of oxalic acid in scent leaf

\begin{tabular}{|l|c|}
\hline \multicolumn{1}{|c|}{ Parameter } & Absorbance \\
\hline A & $0.198 \pm 0.440$ \\
\hline B & $0.211 \pm 0.450$ \\
\hline B & $0.219 \pm 0.460$ \\
\hline E + filtrate & $0.031 \pm 0.180$ \\
\hline
\end{tabular}




\section{Discussion}

Phytochemical analysis is of a paramount importance in identifying new sources of therapeutically and industrially valuable compounds having nutritional and medicinal properties [13]. Traditional herbs are generally cheaper, accessible or readily available and more culturally acceptable to many. Furthermore, some synthetic drugs have been associated with some side effects, thus many turn to traditional herbs as complementary therapies and for preventive medicines. Plants thus, are used as medicinal plant in many countries of the world to manage tumour, diseases associated with oxidative stress and in countries with improved health care [14, 15].

The results of the phytochemical analysis of this study confirmed the presence of spaonin, tannins, flavonoids, steroids, terpenoids and phenols. These secondary metabolites like the steroids, flavonoids and alkaloids are all valuable medicinal plants which are widely used in many traditional cultures and are increasingly becoming popular in modern society as natural alternatives to synthetic medicines. According to [16] exploitation of plant using modern biotechnology in purification, separation of compounds and metabolic engineering have produced important compounds that may function as antioxidant, anti-inflammatory and antimicrobial compounds.

According to [8], steroids are useful in diabetes, arthritis, ulcer and stomach ache. People also use them in some sports settings to boost muscle mass, performance, endurance and to shorten recovery time between workouts. Steroids are artificially derived from the main male hormone testosterone which is important for promoting and maintaining muscle growth and developing secondary male sex characteristics, such as a deepening voice and facial hair.

Flavonoids have been reported to exhibit other multiple biological effects, antiviral, antibacterial, anti-inflammatory, vasodilatory, anticancer, anti-ischemic, etc. [17]. Since there has been a global upsurge in the incidence of cancer, hypertension and other diseases related to oxidative stress especially in developing countries, plant sources containing flavonoids will be very helpful.

Phenols present in plants have powerful medicinal effects as it can help to manage ulcer and cancer. More so, phenols and glycosides are both powerful secondary metabolites with enormous antioxidant activities, these metabolites also contains vitamins which pays a vital role in human health.

Oxalic acid also known as ethanodioic acid is a naturally occurring compound which in many different types of vegetable [18]. For human, oral and tropical applications of this acid are highly toxic to the body due to its bleach like and corrosive properties [18]. These properties are however, useful for waste water applications and general cleaning and therefore this acid is commonly employed for this purpose today. The oxalic acid is an ideal chemical for cleaning purposes. Its bleach like quality makes it perfect for stylizing household items. It is also efficient in removing rust on various different surfaces [19]. Stains on counters, bath tubs and kitchen sinks can be removed through careful application of this chemical. Today, it can be found as a passive ingredient in various cleaning products, bleaches and detergents. It is used medically to purify chemicals. Oxalic can cause unwanted side effect to those who ingest a high amount of food containing the chemical or use drugs with concentrated amount of it present [19].

However, oxalic biopesticidal effect are seen or applied in form of fertilizer during plant cultivation, it helps to enhance the growth of plants when applied just like fertilizer. Any alternative to the use of chemical pesticide to the use of chemical pesticide will be a highly welcome approach. The oxalate content of neem plants have also been determined [20] and there is the need for more exploration of oxalate contents of range of plants.

\section{Conclusion}

The study shows that scent leaf extract has an enormous medicinal value as indicated by the metabolites present in the plant extract. Further, it can be exploited in biopesticidal application due to oxalic acid.

\section{Compliance with ethical standards}

\section{Acknowledgments}

The authors wish to acknowledge the HOD Department of Applied Biochemistry Enugu State University of Science \& Technology Enugu State Nigeria, Dr. M.O. Ezenwali for his guide. The authors are profoundly grateful staff of Applied Biochemistry Laboratory where this research was carried out. 


\section{Disclosure of conflict of interest}

There is no conflict of interest in this research article.

\section{References}

[1] Srinivasa PS, Jagadeesh TC. Health Benefit of medicinal plant. Austria Journal of Medicinal Science. 2008; 11(2): 102-115.

[2] Kumar AD, Chandra CJ,Dada CB. Medicinal Plant of Nigeria. Antimicrobial and Chemo-preventive Properties of Herb and Spices. Journal of Chemistry. 2008; 11(11): 1450- 1460.

[3] Kalra AR, Khanuda DD. Plant Derived Pestidal Antimicrobial Agents for use inAgriculture- A review of Phytochemical and biological studies on some Nigerian Plants.Journal of Agricultural Science. 2007; 5: 330-336.

[4] Gupta SS, Dikshit AR. Phytochemical Constituents of Scent leaf; and their Health Implication on Some Microorganism Journal of Pharmaceutical Science. 2010; 5(3): 97- 101.

[5] Kumar DJ, Singh AS. The useful Plant in East Tropical Handbook. American Journal of Biological Sciences. 2014;7:455-459.

[6] Bokier, James CS. General Classification of Ocimum gratissimum. Journal of Biological Sciences. 2011; 5(12): 1160-1163.

[7] Salma-Mazid SI. Scent Leaf and its Health Implication. Journal of Health Science. 2011; 6(1): 368-384.

[8] Aggarwal CS, Arfan F, Ghadirian E, Cabrer BD, Arambulo PV. Epidemiology and Biopestidal Action on Organism"s.American Journal of Tropical Medical Sciences. 2011; 26(5): 866-871.

[9] Everitt GO, Idris S, Ndamito MN, Ebenezer IB. The Phytochemical Screening of Plants Constituents. International Journal of Biological Resources. 1995; 2(1): 76-87.

[10] Nwankwo, Chibuzo S, Ebenezer Ike A, Ikpeama Ahamefula I, Asuzu Francess O.The Nutritional and and the Antinutritional Values of two Culinary Herbs, Scent Leaf (Ocimum gratissium) and Uziza Leaf (Piper guineense) popularly used in Nigeria. International Journal of Scientific \& Engineering Research. 2014; 5(12):1160-1163.

[11] Trease SN, Evans N, Rowrey Z. Spectrophotometric Reaction Rate Method ForDetermination of Oxalic Acid in Food Based on its Enhancing Effect on the Oxidation ofPyrocathecol Violet by Dichromate. Journal of Biology and Chemistry. 1998; 144: 321-332.

[12] Sofowora A. Medicinal Plants and Traditional Medicine in Africa (2nd ed.). Ibadan, Nigeria: Spectrum Books Ltd. 1993.

[13] Abba PO, Moussa D, Eric FS, Tanoh HK. Phytochemical Analysis, Purification and Identification of HibiscusAnthocyanins. Journal of Pharmaceutical, Chemical and Biological Sciences. 2015; 3(2):156-168.

[14] Dephande, S.S., Ingle, A.D., and Maru, G.B.(1998). Chemopreventive efficacy of curcumin free aqueous extract in 7, 12-dimethylbenz[a]anthracene-induced rat tumorigenesis. Cancer Letters, 123:35-40.

[15] Dorai, T. Gehani, N. and Katz, A. (2000). Therapeutic potential of curcumin in human prostate cancer II. Curcumin inhibits tyrosine kinase activity of epidermal growth factor receptor and depletes protein. Molecular Urology, $4 ; 1-6$.

[16] Milugo, T.K., Omosa, L.K., Ochanda, J.O. et al(2013). Antagonistic effect of alkaloids and saponins on bioactivity in the quinine tree (Rauvolfia caffra sond.): further evidence to support biotechnology in traditional medicinal plants. BMC Complement Alternative Medicine, 13:285.

[17] Procházková, D., Bou ová ,I. and Wilhelmová, N. (2011). Antioxidant and prooxidant properties of flavonoids. Fitoterapia, 82:513-523.

[18] https://elmaskincare.com/h menu/oxalic acid.htm. Oxalic acid, accessed 19th August, 2021.

[19] http://cameo.mfa.org/wiki/Oxalic acid. Oxalic acid, Accessed 19th August, 2021.

[20] Ujah II, Nsude CA, Ani ON, Alozieuwa UB, Okpako IO,Okwor AE. Phytochemicals of neem plant (Azadirachta indica) Explains its use in Traditional Medicine and Pest Control.GSC Biological and Pharmaceutical Sciences. 14(02): 165-171. 